\title{
La desaceleración metropolitana y su reflejo en la realidad urbana del occidente europeo
}

\author{
Carmen muguruza Cañas * \\ José Miguel Santos Preciado *
}

\section{INTRODUCCIÓN}

La literatura urbanística de los años sesenta nos había acostumbrado a establecer una relación directa entre desarrollo económico y concentración urbana. Desde el siglo pasado, las tendencias inherentes al proceso de la revolución industrial confirmaban la progresiva concentración de la población en ciudades millonarias, siguiendo el modelo territorial metropolitano. Los flujos migratorios del campo a la ciudad eran la consecuencia lógica de la transformación del sistema productivo de un pais agrario a otro industrializado y post-industrializado, uniendo en un binomio común los términos de urbanización e industrialización.

Sin embargo, desde el comienzo de los años sesenta, los movimientos migratorios de los paises desarrollados comenzaron a cambiar su signo, desacelerando el crecimiento de las grandes urbes y provocando el ascenso de las ciudades de tamaño medio e inferior de la jerarquia urbana. La evolución ha sido similar en la mayor parte de los países occidentales. En Estados Unidos, esta tendencia comenzó a hacerse sentir en el censo de 1970 y llegó a generalizarse en el de 1980. En Europa, el proceso ha sido semejante, si bien con un cierto desfase respecto a la realidad urbana norteamericana. Incluso, la situación euro-

* Departamento de Geografía. UNED. 
pea tampoco puede ser considerada como homogénea. Así, mientras las grandes aglomeraciones del Reino Unido, Alemania, Paises Bajos y Norte de Italia y Francia, han seguido los pasos de las ciudades americanas con una mayor rapidez, en los paises mediterráneos del Sur el fenómeno se ha iniciado con unos años de retraso.

La evolución demográfica de los años ochenta resulta más confusa que la de las dos décadas anteriores y el declive de las grandes metrópolis parece lejos de ser general. “En Estados Unidos, los datos anuales sobre migraciones muestran que el balance es menos favorable a las zonas no metropolitanas que en el curso de la década precedente. Los flujos migratorios que se desplazan desde las áreas urbanas hacia las rurales, y viceversa son menos numerosos en conjunto, pero además, la disminución es menos marcada en el primer sentido que en el segundo" (Claval, 1989). Esta realidad parece confirmarse también en algunos países europeos.

Aunque las tendencias generales del momento actual deban ser estudiadas más detenidamente, surge el interrogante de si el proceso de desaceleración de la concentración urbana se está deteniendo o, al menos, se está produciendo de manera desigual. Es éste uno de los debates de mayor interés que ocupa a los urbanistas en el momento presente.

Sin entrar en el mismo, y de forma general, pretendemos analizar la evolución del modelo de crecimiento de las grandes ciudades del mundo desarrollado, así como de los factores que han modificado la localización de las actividades económicas, fenómeno, este último, que está en la base de la descentralización y cambio del modelo territorial actual.

\section{EL MODELO METROPOLITANO DE LA ETAPA DESARROLLISTA: GESTACION Y CRISIS}

El modelo territorial metropolitano ha sido la consecuencia de la concentración de la población y el empleo en grandes ciudades, al amparo de las economías de escala y aglomeración. Esta concentración de los factores productivos y de consumo en un reducido espacio geográfico era la respuesta, espacialmente estructurada, a un modo de producir y vivir en el que todos los agentes sociales que intevienen en la construcción de la ciudad (bancos, promotores inmobiliarios, constructores, organismos públicos, ...) participaban de un sentido autoperpetuador del crecimiento, como fin en sí mismo. El fenómeno se realimentaba, «fo- 
mentado por el aumento de la población, la emigración, la concentración de servicios, las inversiones, los progresos industriales y muy especialmente, por el rápido y flexible transporte automovilístico" (Esteban, 1981: 23).

Este proceso de crecimiento ha ido consolidándose en diversas etapas. En un primer momento, tuvo lugar una concentración en el centro de la metrópoli. En esa fase, «la ciudad metropolitana monopolizó durante un tiempo la mayor parte del crecimiento demográfico y de actividades de su área natural, con una ocupación intensiva de su espacio libre y la consiguiente elevación de su densidad geográfica" (Esteban, 1981: 24). Este periodo constituyó la etapa de crecimiento de carácter centrípeto.

En la segunda fase, el crecimiento progresó hacia el exterior, de forma centrífuga. En la literatura anglosajona se acuñó el término "suburbanización" para designar el rápido crecimiento expansivo hacia los suburbios o periferia metropolitana. El proceso ha tenido un carácter diferente (sobre todo en lo que a tipología de vivienda se refiere) en los países de la órbita anglosajona - principalmente en Estados Unidosque en la mayoría de los países europeos, aunque en todos ellos la metrópoli se ha extendido tan lejos como los medios de transporte permitían los desplazamientos diarios de los "commuters", definiéndose así el "área metropolitana» como un gran área de interrelación, de producción y consumo diarios.

Este movimiento centrífugo progresó en varias sub-fases. En la primera, «la ciudad llegó a apoderarse de los pequeños centros periféricos que en su día constituian suburbios autónomos. Posteriormente, la ciudad tendió a absorber pueblos e incluso pequeñas ciudades situadas, a veces, a considerable distancia del centro". Por último, el proceso de expansión no se ha desarrollado sólo en dirección única. El crecimiento de cada núcleo central tropieza con otros análogos y de signo contrario que al expandirse se acercan a aquél, acentuando cada vez más el carácter urbano de la zona a costa del sector rural" (Esteban, 1981: 25). (Figura 1).

El resultado coincide, en un alto porcentaje, con el modelo territorial definido por $\mathrm{H}$. Blumenfeld en su obra "The modern metropolis" (Blumenfeld, 1972), donde el autor nos sugiere un cambio del modelo de ciudad tradicional al metropolitano. Sus rasgos más representativos serían:

- Concentración de la población en grandes metrópolis.

- Separación de los lugares de residencia y trabajo. 


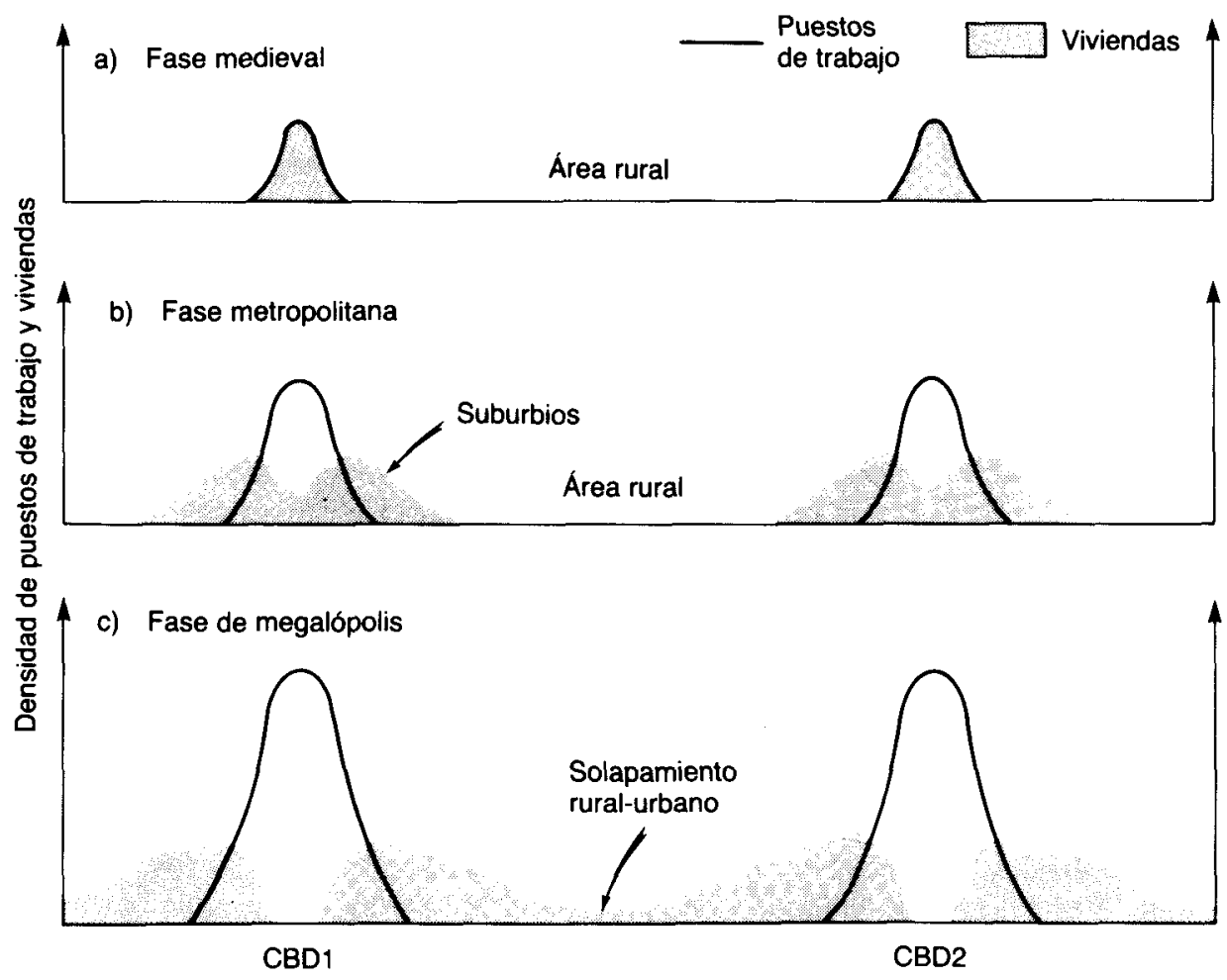

Fig. 1. Modelo simplificado del crecimiento en extensión de dos ciudades (concepción desarrollista).

Fuente: P. Hagget: “Geografia. Una síntesis moderna». 
- Concentración del sector terciario en el centro de la ciudad.

- Expulsión hacia la periferia de las funciones residencial e industrial.

- Segregación sectorial de la vivienda según clases sociales.

Este modelo metropolitano, donde la suburbanización ha dominado en su fase de madurez, encontró en el transporte por automóvil uno de los pilares básicos de su mantenimiento. La diferenciación funcional de la metrópoli ha ido evolucionando con el paso del tiempo. La originaria concentración de los servicios terciarios en el centro de la ciudad ha dado paso a una progresiva descentralización de alguno de ellos. Así, gran parte de los grandes centros comerciales y de los edificios de oficinas han abandonado los centros primitivos, transformando la estructura de las metrópolis en espacios policéntricos. En los casos extremos de Estados Unidos y Australia, el sistema metropolitano presenta actualmente, aparte de un CBD clásico, restringido a determinados usos del suelo específicos: financieros y de recreo y espectáculos, un tejido indefinido de hábitat unifamiliar, salpicado de grandes subcentros comerciales y de oficinas. Además, las funciones urbanas, residencial e industrial, han ampliado su nivel de descentralización primitivo. Las nuevas pautas de localización industrial metropolitana han ampliado los límites de la expansión. Aún conservando cierta conexión con la metrópoli, las empresas industriales han buscado la dispersión en un radio de 200-250 kilómetros del centro de la aglomeración, conservando así ciertas ventajas de la proximidad al mercado de la gran ciudad.

La congestión de las grandes urbes ha transformado las economias de aglomeración en economias de desaglomeración. Las elevadas densidades de poblamiento han degradado el medio ambiente urbano hasta límites que hacen comprensible el deseo de cambio del lugar de residencia. No es extraño, que a partir de un cierto momento llegaran a invertirse las tendencias concentradoras y aparecieran otras nuevas de carácter descentralizador.

A partir de la década de los años sesenta, primero de una manera lenta e individualizada y después de forma más general ha aparecido una nueva fase del desarrollo urbano, caracterizada por el crecimiento lento o negativo de muchas áreas metropolitanas, acompañada por un incremento de las tasas de crecimiento de las ciudades de tamaño medio $\mathrm{e}$ inferior e incluso de las áreas rurales. Este fenómeno descrito por D. Vinning como "de ruptura clara con el pasado" (Vinning, 1982) subraya la diferencia fundamental con la fase de suburbanización e incluso supera los conceptos de periurbanización o rururbanización (utilizados para defi- 
nir áreas difusas de contacto de la realidad urbana y rural). El mismo ha sido definido con diferentes conceptos, de contraurbanización (Berry, 1976), desconcentración metropolitana (Long, 1981), desurbanización o exurbanización.

El cambio ha llevado a los analistas urbanos a preguntarse si ha terminado la etapa de las grandes aglomeraciones urbanas y ha comenzado una nueva de despoblación de las mismas. La respuesta no es sencilla y exige, al menos, responder a otros interrogantes concomitantes con el proceso de desaceleración observado.

\section{PRINCIPALES CAUSAS DE LA DESACELERACIÓN Y DECLIVE DE LAS GRANDES AGLOMERACIONES URBANAS}

Los factores que han influido en el cambio de modelo del crecimiento urbano son variados y están siendo analizados por los estudiosos de la ciudad. El despoblamiento de las metrópolis actuales exige un análisis detallado de las causas que han determinado la modificación de los dos elementos fundamentales de la dinámica demográfica: el crecimiento natural y el componente migratorio. Las grandes corrientes migratorias del campo a la ciudad de la etapa desarrollista determinaron que una población joven con una alta tasa de fertilidad se estableciera en las aglomeraciones urbanas, provocando un "boom" de crecimiento sin precedentes. Hoy en día, las circunstancias se han modificado radicalmente. A los factores de retracción interna de la ciudad, causados por la reorganización del sistema productivo, hay que sumar las nuevas pautas de comportamiento demográfico que están disminuyendo sustancialmente las tasas específicas de fertilidad, en una población que, además, tiende progresivamente hacia el envejecimiento.

Para facilitar la exposición de la transformación del modelo metropolitano en los paises desarrollados de la órbita occidental, comenzaremos analizando las principales teorias explicativas del decrecimiento de las metrópolis y de los factores subyacentes al mismo, para terminar definiendo el modelo territorial metropolitano más consecuente con la nueva etapa de crecimiento urbano.

\subsection{El encuadre teórico de la desaceleración metropolitana}

W. H. Frey (Frey, 1988) nos ofrece una perspectiva teórica desde la que centrar el análisis del proceso de desaceleración metropolitana. Se- 
gún este autor, existirian dos teorias fundamentales que podrian servir de marco al planteamiento del problema. La primera, denominada «teoría de la reestructuración regional», considera que «las últimas tendencias demográficas reflejan una representación espacial de los cambios habidos en la organización de la producción y en las funciones que las áreas afectadas desempeñan en la nueva organización. Estos cambios en la organización de la producción vendrían determinados por una expansión a nivel mundial de los mercados y de las actividades productivas, por una división territorial del trabajo entre países y, en las naciones desarrolladas, por una transformación de la industria hacia el sector servicios, que están dando lugar a nuevas formas de organización empresarial y a tendencias de crecimiento polarizado entre las distintas regiones y áreas metropolitanas" (Frey, 1988: 7). Según esta teoría, aquellas áreas que se conviertan en centros de control y dirección dentro de la jerarquía de las tomas de decisión, por ser portadoras de servicios de alto nivel o de centros de investigación y desarrollo, aumentarán la concentración demográfica en detrimento de aquellas otras ancladas en la industria más tradicional, más afectada por la crisis.

No todos los autores defensores de esta tendencia adoptan una posición homogénea respecto al origen desencadenante del proceso. Así, mientras unos ponen el acento en la post-industrialización, en las innovaciones tecnológicas y nuevos descubrimientos de la telecomunicación, otros lo harían en la desindustrialización. Estos últimos, aun reconociendo la importancia de los factores antes reseñados, consideran que los mecanismos desencadenantes de la nueva tendencia de despoblamiento urbano, tendrian su raíz en la crisis económica de los años setenta que forzó a los capitalistas a desinvertir en determinados sectores y en las áreas donde éstos estaban localizados.

Por su parte, «la teoría de la desconcentración» prevé un gradual y sostenido despoblamiento de las grandes áreas metropolitanas de manera generalizada. "Esta teoría pone menos énfasis en la nueva organización de la producción como causa de la distribución regional, a la vez que atribuye un mayor protagonismo a las preferencias de los consumidores sobre su lugar de residencia, y a su interrelación con las decisiones de la localización del empleo" (Frey, 1988: 16). La últimas innovaciones de la tecnología del transporte y de las comunicaciones favorecerian la organización del espacio sobre nuevas bases $y$, de esta manera, el espacio productivo estaría mucho más determinado por las preferencias residenciales de los trabajadores.

Ambas teorias ponen el acento, de manera diferenciada, en un conjunto de factores que han modificado la reorganización productiva des- 
pués de la crisis económica y su modelo territorial consecuente. Analicémoslos separadamente.

\subsection{Los factores condicionantes de la reorganización urbana actual}

Personalmente, consideramos, que la problemática urbana actual debe examinarse en relación con el nuevo modo de producción y con la capacidad de adaptación a las circunstancias económicas que condicionan el desempeño de las funciones urbanas. Concebido en un sentido amplio, el sistema productivo estaría relacionado con la revolución tecnológica y con los cambios socio-culturales que están produciendo transformaciones esenciales en la estructura de la población. Veamos cada uno de los tres tipos de factores de manera individualizada.

\section{Factores inherentes a la reorganización del sistema productivo}

La crisis económica de los años 70 ha supuesto la reorganización del modelo de crecimiento económico, lo que afecta a una serie de rasgos básicos del sistema productivo, con evidentes repercusiones en la localización de los centros de actividad.

El primer rasgo a destacar es la internacionalización, e incluso, “mundialización» (Santos, 1984: 63), de la economía, causada por una nueva división internacional del trabajo. La elevación de los precios de la energía y de la mano de obra en los paises tradicionalmente productores de mercancías ha trasladado los sectores más intensivos en trabajo a los nuevos países industriales como Taiwan, Corea del Sur, Singapur o Hong-Kong, donde la remuneración de la fuerza de trabajo es más baja. Esta tendencia a la deslocalización afecta básicamente a determinados escalones y sectores del aparato productivo, como la transformación de recursos minero-energéticos en las primeras fases de la producción, fabricaciones de gran poder contaminante $y$, sobre todo, a determinados tipos de industria ligera, necesitados para su fabricación de un elevado porcentaje de mano de obra directa.

La reconversión económica interna de los países desarrollados ha estado marcada por la necesidad de acomodación del sistema productivo a las nuevas exigencias técnico-organizativas planteadas por la crisis económica. "Durante decenios, el sector industrial que fue el exponente paradigmático del crecimiento económico de estas sociedades (hasta el punto de ser habitual la identificación entre industria y desarrollo) y, generador de buena parte de los fenómenos de concentración espacial tí- 
picos de la fase de gestación y maduración del modelo metropolitano, se ha visto afectado por procesos de reestructuración y declive de empresas, sectores de actividad y áreas fabriles de notable tradición e importancia en muchos casos» (Méndez, 1986). La urgencia de la transformación del sistema productivo industrial ha estado presionada por la inflación de costes (energia, materias primas, mano de obra) a que antes hemos hecho referencia, asi como por la elevación de costos financieros y presión fiscal sobre las empresas, en un momento en que la competencia externa y la obsolescencia tecnológica ahogaban cualquier posibilidad de rentabilidad económica.

La reorganización del sistema industrial como respuesta a la crisis, ha llevado consigo una rápida incorporación de las innovaciones tecnológicas en el proceso productivo, sustituyendo trabajo por capital, al tiempo que ha creado las bases necesarias para una descentralización y fragmentación de las diversas fases de la producción. El resultado de esta política empresarial ha tenido importantes consecuencias en la diferenciación intersectorial del ritmo de crecimiento económico, así como en la localización y formas organizativas de la actividad industrial. Asi, el sector secundario ha tendido a perder peso en las economías de los países occidentales respecto al sector servicios.

Este proceso no afecta únicamente al desarrollo de determinados subsectores típicamente terciarios, sino a la propia actividad industrial, pues cada vez son más las personas que no realizan tareas productivas directas (departamentos de marketing, financiero, informática, etc). La producción, por tanto, se inmaterializa y terciariza, trabajando más personas en la prestación de todo tipo de servicios. Dentro de ellos, juegan hoy dia un papel fundamental los servicios denominados avanzados, como proyectos de ingeniería, investigación y desarrollo y planificación o aquellos otros derivados de las finanzas y de la administración pública y privada. A nivel industrial, la industria de la alta tecnología, electrónica y de telecomunicación, mantiene mayores posibilidades de expansión frente a la industria siderúrgica o naval, claramente en retroceso.

Las nuevas estrategias de la economía industrial han llevado a la descentralización del proceso productivo y a la dispersión y deslocalización de la actividad. Buena parte de la producción que antes se realizaba en la gran empresa ha sido segmentada, subcontratándola a empresas o talleres de menor tamaño. Se busca con ello reducir los costes laborales e incluso la especialización técnica en unidades productivas más reducidas, donde la precarización del empleo en áreas de baja implantación sindical suele ir acompañada de reducción de los salarios y de las cargas empresariales. El caso extremo lo constituiria la economía sumergida, 
donde el trabajo negro sin Seguridad Social y bajos salarios se sumaria la evasión de cargas legales. Además, la localización espacial de las nuevas unidades productivas tiende hacia la difusión en regiones periféricas, alejadas muchas veces de las grandes aglomeraciones urbanas, donde el precio elevado del suelo se convierte en una rémora para su implantación.

\section{Factores derivados de la revolución tecnológica}

Una segunda serie de rasgos a destacar se derivan del impacto directo de las nuevas tecnologias sobre la organización espacial de las actividades económicas. "Toda organización social es un sistema de comunicación. Su papel consiste en recoger las informaciones, ponerlas en memoria, tratarlas y utilizarlas en el momento en que las decisiones deben ser tomadas" (Claval, 1989). La revolución tecnológica actual, apoyada en la informática y la telemática, esta modificando radicalmente la forma de transmitir y centralizar la información. Antes del desarrollo de la tecnología informática, la adquisición y la organización de la información era una operación larga, que requería la intervención de un gran número de trabajadores en las tareas de inventariado y contabilidad. La dificultad de centralizar la información obligaba a una mayor autonomía de los diversos establecimientos fabriles de una empresa, a la hora de tratar directamente con proveedores y clientes. Esta misma dificultad de coordinación aconsejaba la proximidad de las fases de producción y control.

Actualmente, los establecimientos periféricos de la empresa pueden mantener una mayor autonomía locacional, al posibilitar las nuevas técnicas de la comunicación la centralización automática de la información. La contigüidad espacial ha pasado a un segundo plano y se asiste asi a una deslocalización de determinadas actividades, sobre todo de las oficinas. La situación actual permite la existencia de unidades centralizadas de alto nivel y de sub-centros descentralizados en lugares más alejados.

Es cierto, también, que la mejora de relaciones establecidas por las telecomunicaciones no resuelve el problema del todo. Las necesidades de contacto personal entre los trabajadores más cualificados y ejecutivos nos obliga referirnos a las técnicas de transporte de alta velocidad. La ubicación de las empresa industriales y de servicios debe considerar como factor de primer orden la situación respecto a las principales redes de transporte. Incluso, muchos de los establecimientos dispersos se implantan en áreas localizadas a una distancia de un aeropuerto no superior a los $30-50 \mathrm{~km}$. 
En conjunto, las nuevas tecnologías de la comunicación y del transporte favorecen el desarrollo de la difusión en el espacio y una mayor descentralización de la actividad económica.

\section{Factores socio-culturales y demográficos}

Un tercer conjunto de factores son aquellos de carácter socio-cultural que están evidenciando una gran transcendencia en la estructura y distribución espacial de la población.

En primer lugar, habría que destacar el proceso de transformación de la familia nuclear patriarcal. La incorporación de la mujer al trabajo y las nuevas pautas culturales y sociales, han modificado la estructura de las tasas específicas de fertilidad femeninas. En conjunto, éstas han disminuido y desplazado hacia cohortes de población de mayor edad, disminuyendo el número de hijos de cada unidad familiar. Este hecho ha tenido como consecuencia la ralentización de la dinámica poblacional y ha cambiado las pautas de crecimiento natural en el mosaico intraurbano de la ciudad.

Además, la mayor presencia de la mujer en el mundo laboral ha añadido nuevos elementos a considerar. Para muchas parejas, la dimensión del mercado de trabajo resulta un dato esencial en el momento de la elección del lugar de residencia. A la hora de la toma de decisión es importante seleccionar aquellos lugares que ofrecen mayor diversidad de ofertas de trabajo, pensando en la posibilidad de un cambio de puesto laboral. En este sentido, las pequeñas ciudades aisladas o las áreas rurales pueden resultar un handicap.

En tercer lugar, al envejecimiento progresivo de la población hay que añadir las crecientes tasas de divorcio y separación, así como la disminución de las tasas de nupcialidad y el incremento consecuente de las personas solteras. Todos estos factores tienden a la reducción del número medio de personas que habitan una vivienda. Esta mayor individualización de la vida cotidiana tiene consecuencias importantes en la relación población-parque de viviendas, así como en el tipo de equipamientos que una ciudad debe disponer.

\section{UNA VISIÓN AMPLIADA DEL PROCESO DE CONFORMACIÓN METROPOLITANO}

Hasta aquí, hemos analizado los factores más importantes que están determinando la nueva estructuración del sistema urbano en los países 
desarrollados. Es quizás, el momento, de exponer el modelo territorial que se está gestando sobre la base de una nueva relación centro-periferia.

\subsection{Etapas de la evolución metropolitana}

El fenómeno metropolitano en los países occidentales ha sido la consecuencia espacial de la concentración de los factores productivos en la ciudad. Por este motivo, la aparición de las tendencias descentralizadoras de la desindustrialización ha producido un gran impacto en las grandes aglomeraciones urbanas, cuya respuesta, aunque variada, ha conducido, de manera general, a una pérdida de funcionalidad en el sistema productivo y al denominado "declive urbano". Sin embargo, las fuerzas de inercia juegan a favor de su mantenimiento. La concentración de capital e infraestructuras que las grandes ciudades representan, hace impensable su desaparición. Las áreas metropolitanas clásicas han tenido que replantearse su nuevo papel ante la actual reestructuración del sistema productivo.

Las consecuencias para el nuevo modelo territorial metropolitano han sido de consideración. Antes de tratar de descubrir los nuevos rasgos que lo caracterizan puede resultar interesante integrar las principales variables económicas y demográficas en un modelo general que refleje, de forma evolutiva, las principales etapas del desarrollo metropolitano desde el momento de su gestación hasta el de estancamiento actual, pasando por las fases intermedias de crecimiento rápido y maduración. Estas variables serían, desde un punto de vista demográfico, la población total, los flujos migratorios y la densidad de ocupación del territorio y, desde el económico, la evolución de los componentes sectoriales, la de las economías de aglomeración y la expansión del mercado hacia el exterior.

Luis Suárez Villa expone en su trabajo «Evolución metropolitana, cambio económico sectorial y distribución del tamaño de las ciudades" (Suárez Villa, 1987); un modelo muy ilustrativo de la evolución metropolitana (Cuadro I, figura 2).

El modelo consta de seis fases y contiene el suficiente nivel de detalle como para poner de manifiesto los momentos claves o puntos de inflexión del desarrollo metropolitano. Las fases I y II serían las típicas fases correspondientes al crecimiento rápido de la expansión urbana y la concentración. Estas fases coincidirían con el momento del polo de crecimiento de la metropolitanización. En ellas, el empleo industrial crece rápidamente, mientras que el del sector servicios, aún significativamente, 
La desaceleración metropolitana y su reflejo en la realidad urbana ...

\begin{tabular}{|c|c|c|c|c|c|c|c|c|c|c|}
\hline $\begin{array}{l}5 \\
4 \\
w \\
w \\
4\end{array}$ & 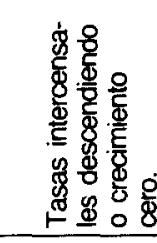 & 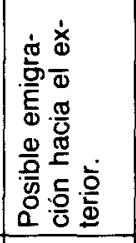 & 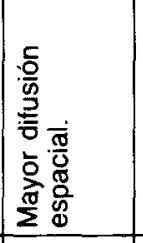 & 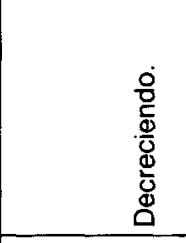 & 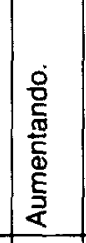 & 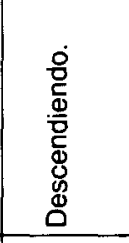 & 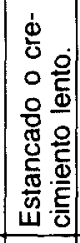 & 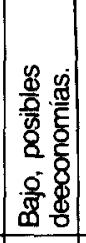 & & 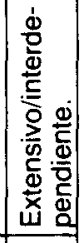 \\
\hline $\begin{array}{l}\vec{w} \\
\text { w } \\
\text { w } \\
\underline{4}\end{array}$ & 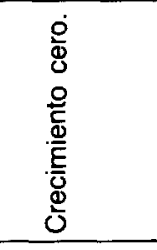 & 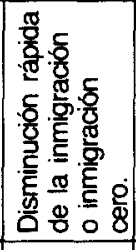 & 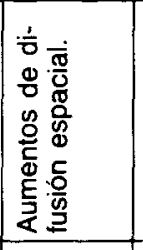 & 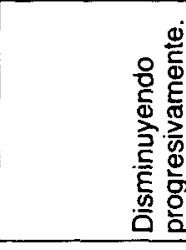 & 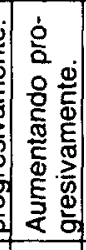 & 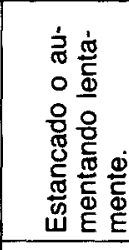 & 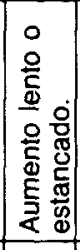 & 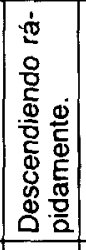 & 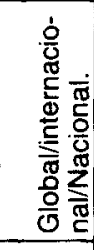 & 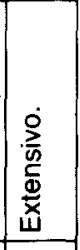 \\
\hline $\begin{array}{l}\geq \\
\underset{w}{w} \\
\frac{w}{4}\end{array}$ & 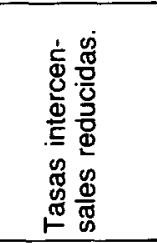 & 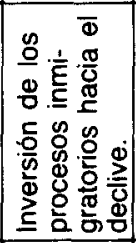 & 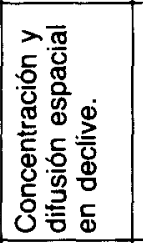 & 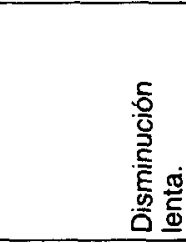 & 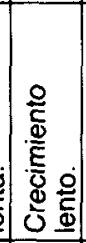 & 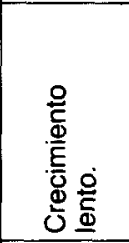 & 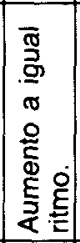 & 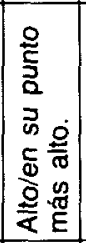 & 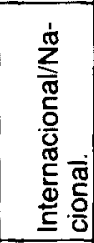 & 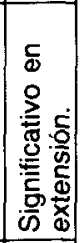 \\
\hline $\begin{array}{l}\Sigma \\
\underline{w} \\
W \\
\mathbb{L}\end{array}$ & 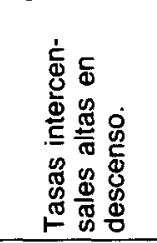 & 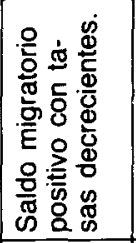 & 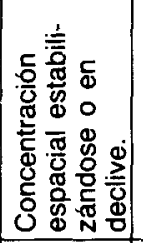 & 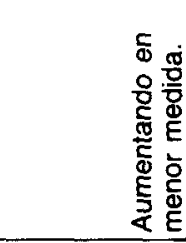 & 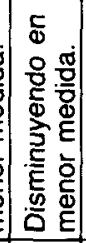 & 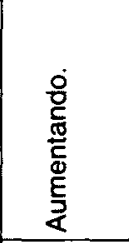 & 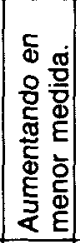 & 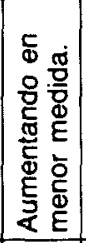 & 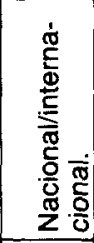 & 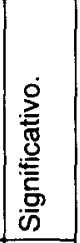 \\
\hline 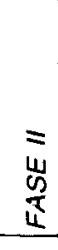 & 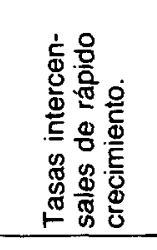 & 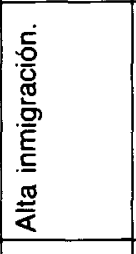 & 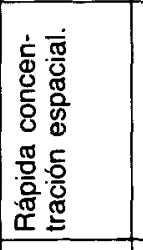 & 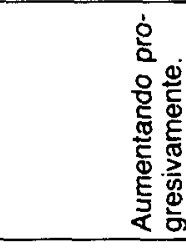 & 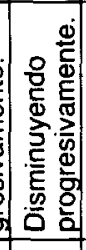 & 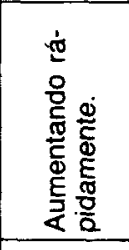 & 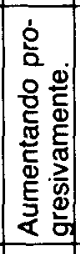 & 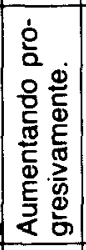 & 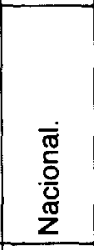 & 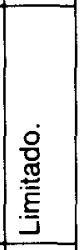 \\
\hline $\begin{array}{l}\vec{w} \\
\underline{w} \\
\underline{w} \\
\underline{L}\end{array}$ & 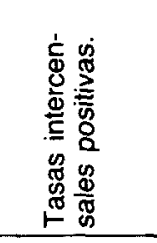 & 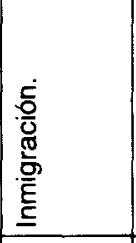 & 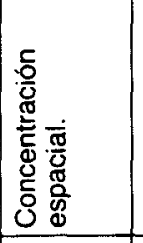 & 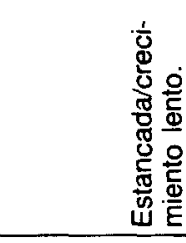 & 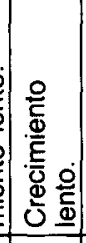 & 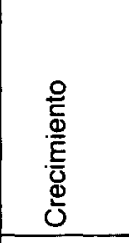 & 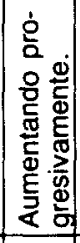 & 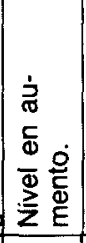 & 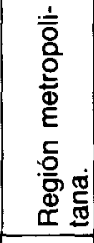 & 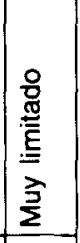 \\
\hline & 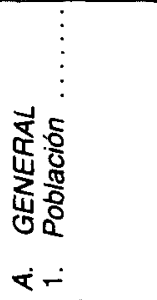 & 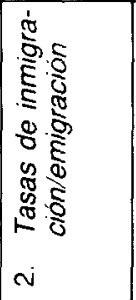 & 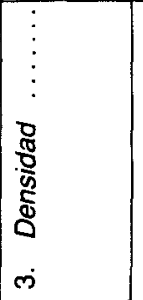 & 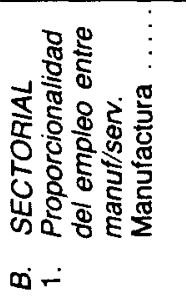 & 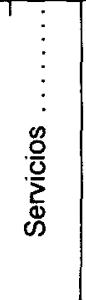 & 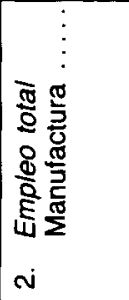 & 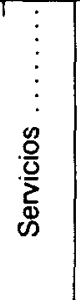 & 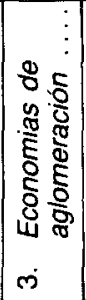 & 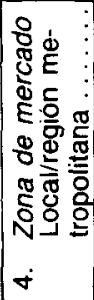 & 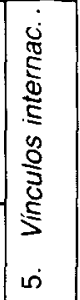 \\
\hline
\end{tabular}



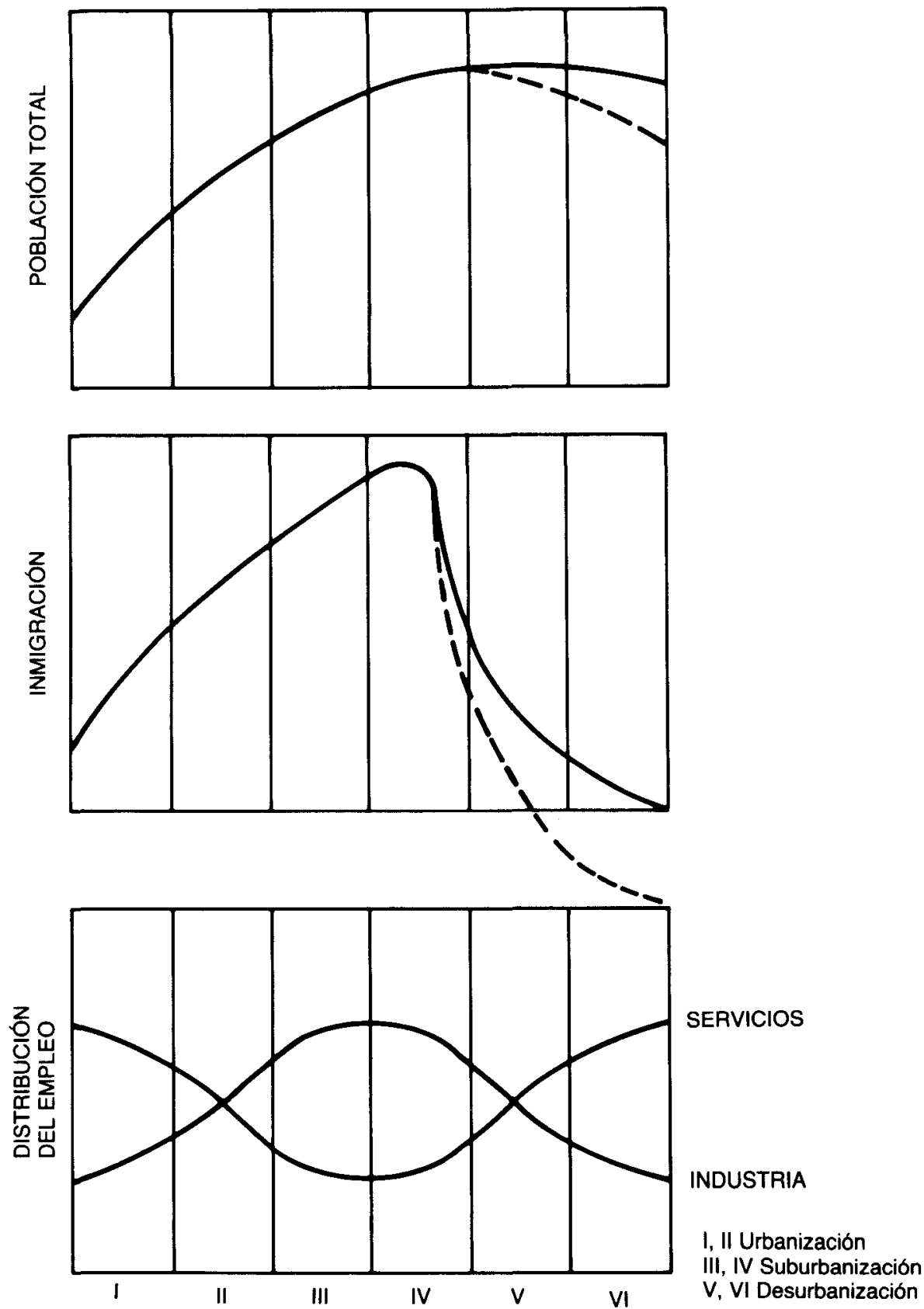

Fig. 2. Etapas de crecimiento metropolitano. 
lo hace a un ritmo inferior, por lo que empieza a declinar en términos relativos. Además, los vinculos interregionales de la industria son cada vez más importantes a medida que la industria local desarrolla canales comerciales a nivel nacional.

El efecto de la dinamización económica, provocado por la concentración del empleo, se manifiesta en un incremento fuerte de las corrientes inmigratorias y del volumen de la población y en un aumento de la densidad de ocupación espacial. Los mayores salarios y las oportunidades de empleo generan grandes flujos migratorios del campo a la ciudad.

Las fases III y IV pueden definirse como de madurez metropolitana. Coinciden ambas con un período de estabilización e incluso de descenso porcentual del empleo industrial. Este período de ralentización del crecimiento se refleja en un claro descenso del crecimiento demográfico y de las corrientes inmigratorias.

Por último, las fases V y VI corresponderian con la etapa de decadencia o declive metropolitanos. En ella, la participación económica del sector servicios se hace cada vez más patente, coincidiendo con la descentralización productiva de la industria y el descenso de la intensidad del factor trabajo frente al capital, connatural con el aumento de la productividad generado por las innovaciones tecnológicas. En este momento, las tendencias inmigratorias llegan a reducirse a cero, cambiando incluso de signo y provocando el descenso de las tasas de crecimiento de la población total de las grandes aglomeraciones metropolitanas. En esta tendencia descendente, la población puede incluso llegar a reducir el número de habitantes, superando la emigración de la gran ciudad a un crecimiento vegetativo en progresiva disminución.

La organización de la actividad económica en el espacio se caracteriza por una mayor difusión hacia formas policéntricas, que llegan inluso a superar la fase de suburbanización por la desuburbanización o contraurbanización. El descenso de la calidad de vida consecuente a las economías de desaglomeración (tráfico, congestión, hacinamiento, elevación del precio del suelo, ...) se convierte en uno de los motivos básicos de la emigración.

\subsection{Estadios del desarrollo urbano metropolitano, medidos por el cambio poblacional}

En la breve exposición del apartado anterior hemos resaltado las principales etapas del proceso de conformación de la actual realidad metropolitana. Pretendemos en esta última fase, detenernos en analizar la 
plasmación en el espacio de la desaceleración metropolitana, medida por la progresiva disminución de su crecimiento de población y la distribución intraurbana entre el centro y la periferia suburbana.

Antes de nada, conviene recordar que no se debe establecer una correlación directa entre declive urbano y disminución de la población metropolitana (Cheshire y Hay, 1989). Las tendencias generales se encaminan hacia la disminución de la concentración urbana, pero aun así, las grandes ciudades han respondido de manera muy diversa a la crisis. Así, aquellas poseedoras de una base económica diversificada han podido responder al declive de las zonas tradicionales con el desarrollo de actividades ligadas generalmente a los nuevos servicios y tecnologías. Peor suerte han corrido aquellas áreas urbanas asociadas al monocultivo de sectores de declive (sector naval, siderurgia) donde las medidas de reconversión e industrialización han dado escasos resultados (Lavergne, 1988: 28).

Son varios los autores que han intentado describir el modelo metropolitano de manera evolutiva. En este sentido, destacan los trabajos de Hall y Hay (1980), Van den Berg et al (1982) y Cheshire y Hall (1986) entre otros. El modelo utilizado por Van den Berg et al, posteriormente adoptado por Cheshire y Hay, refleja en ocho fases, las principales etapas de transformación de la estructura metropolitana. Partiendo del concepto de Región Urbana Funcional (RUF), estos autores delimitan un área metropolitana de carácter funcional a partir de un municipio central, concentrador de un determinado volumen de empleo, al que se incorporan, como centro, aquellos municipios contiguos con una densidad de empleo por superficie que supere un límite establecido. P. Cheshire y $D$. Hall fijaron en 20.000 empleos y $12,35 \mathrm{empleos} / \mathrm{Ha}$ los límites mínimos a superar, para delimitar el centro de la metrópoli. Por su parte, el hinterland o aureola periférica estaría definida por todos los municipios contiguos al centro que intercambian, con el mismo, mayor número de «commuters" que con ninguna otra unidad administrativa.

El modelo diferencia, por tanto, dos áreas principales en su estructura: centro y hinterland o periferia y las fases de transformación o cambio, reflejados por el crecimiento o decrecimiento del volumen de población de las mismas (Fig. 3), nos permite establecer una relación directa con las principales etapas del desarrollo metropolitano descritos en el apartado anterior.

La primera etapa (fases I y II) (Cuadro 2) se corresponderia con el denominado periodo de urbanización. Es el momento del despegue metropolitano. El crecimiento de la población se concentra fundamental- 


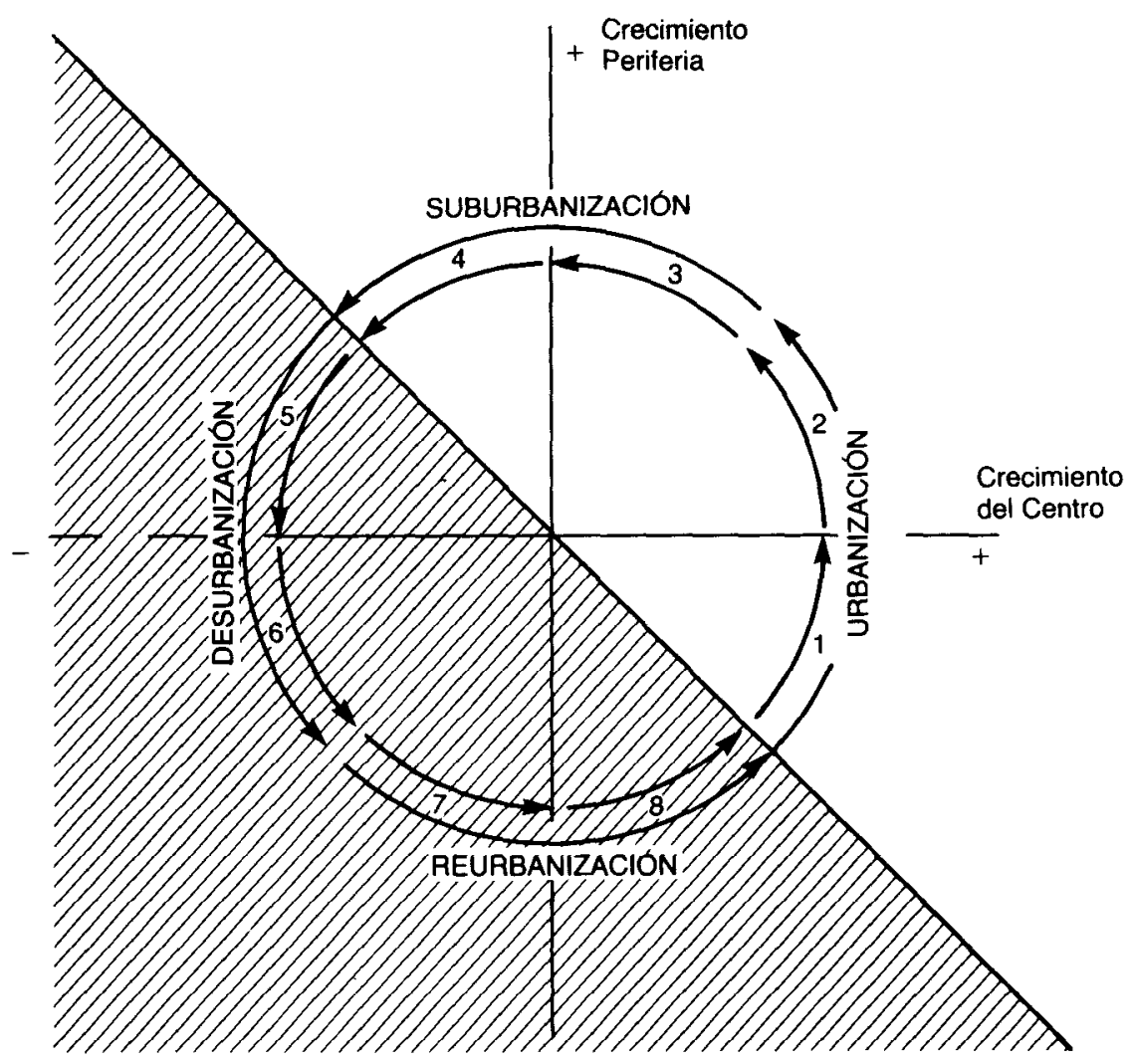

Fig. 3. Fases del modelo de evolución metropolitano.

mente en el centro de la metrópoli. En la fase I, el carácter centripeto de la concentración es tan fuerte que incluso la periferia pierde población en beneficio del centro. En la fase II, el crecimiento de la población es positivo en ambos, aunque con mayor fuerza en el centro que en el hinterland. Coincidiría este período con la etapa I y quizá comienzo de la II del modelo descrito por Suárez Villa, cuando las corrientes migratorias comienzan a ser elevadas como consecuencia de la implantación de empleo industrial en la metrópoli potencial.

La segunda etapa (fases III y IV) es la denominada de suburbanización. En ella, el crecimiento de la ciudad central comienza a descender, al tiempo que se incrementa la población en la corona suburbana. Es el 
CUADRO 2. ESTADIOS DEL DESARROLLO URBANO METROPOLITANO

\begin{tabular}{|c|c|c|c|c|c|c|c|c|}
\hline & \multicolumn{8}{|c|}{ Fases } \\
\hline & \multicolumn{2}{|c|}{ Urbanización } & \multicolumn{2}{|c|}{ Suburbanización } & \multicolumn{2}{|c|}{ Desurbanización } & \multicolumn{2}{|c|}{ Reurbanización } \\
\hline & 1 & 2 & 3 & 4 & 5 & 6 & 7 & 8 \\
\hline Centro (C) & + & + & + & - & - & - & - & + \\
\hline Periferia (P) & - & + & + & + & + & - & - & - \\
\hline RUF $(C+P)$ & + & + & + & + & - & - & - & - \\
\hline & & $\Delta \mathrm{C}>\Delta \mathrm{P}$ & $\Delta \mathrm{C}<\Delta \mathrm{P}$ & & & $-\Delta \mathrm{C}>-\Delta \mathrm{P}$ & $-\Delta \mathrm{C}<-\Delta \mathrm{P}$ & \\
\hline
\end{tabular}

verdadero momento de la conformación metropolitana. Las fuerzas centrífugas actúan descentralizando la actividad económica en un área, cuyos límites van expandiéndose progresivamente hacia la periferia. Las primeras funciones urbanas en ubicarse en la corona metropolitana son la industria y la vivienda, buscando suelo barato y abundante donde poder asentar grandes polígonos industriales y paquetes residenciales de suficiente tamaño como para rentabilizar al máximo la inversión inmobiliaria. Correspondería esta etapa con las II, III y IV descritas en el apartado anterior y supone el momento del máximo crecimiento de la metrópoli y el de ralentización posterior.

La tercera etapa o de desurbanización estaria representada por las fases $V$ y VI. Durante la misma, el débil crecimiento de la periferia metropolitana no supera el decrecimiento de la ciudad central; en consecuencia el área metropolitana pierde población. En la fase sexta, ambas áreas: centro y periferia disminuyen su población. Se correspondería este período con las etapas $\mathrm{V}$ y VI descritas por Suárez Villa, donde los procesos de desindustrialización y difusión espacial, provocados por la reorganización del sistema productivo, serían la causa del descenso poblacional de las grandes aglomeraciones urbanas en beneficio de las ciudades de tamaño intermedio e inferior y áreas rurales.

Por último, la cuarta etapa (fases VII y VIII) o de reurbanización se llevaría a efecto si los programas de renovación, rehabilitación y mejora del centro de la ciudad prosperaran. Es una etapa, aún no alcanzada, al menos de manera importante, y supone una referencia aún teórica del desarrollo urbano de las grandes metrópolis. En ella, el crecimiento del centro iria ganando peso respecto al hinterland, llegando a ser incluso positivo en la fase final. 


\section{LA DESACELERACIÓN METROPOLITANA DE LAS PRINCIPALES AGLOMERACIONES URBANAS DEL OCCIDENTE EUROPEO}

La información disponible sobre la distribución de población en las principales áreas metropolitanas europeas, y su variación en el tiempo, parece confirmar la hipótesis de que el modelo de desaceleración metropolitana puede aplicarse, con carácter general, en la mayor parte de los países de la órbita occidental. "Aunque existan muchas diferencias entre Estados Unidos y Europa, derivadas del diferente modo de vida, las fuerzas generadoras del cambio son comunes en ambos y lo que ha sucedido en el primer país anticipa los modelos de cambio europeos" (Cheshire y Hay, 1989). Así, desde los años cincuenta en Estados Unidos y los sesenta en Europa, la suburbanización ha dado paso a la descentralización metropolitana o a la desurbanización. El resultado ha sido la pérdida relativa del papel desempeñado por los factores favorecedores de la concentración y la pérdida de población de las grandes aglomeraciones urbanas.

El estudio realizado en 1980 por $P$. Hall y D. Hay, así como los posteriores de Van den Berg et al y $\mathrm{P}$. Cheshire y $\mathrm{D}$. Hay muestran, como, empíricamente, las grandes urbes europeas tienden a acomodarse al modelo de evolución metropolitano en sus diversas etapas de urbanización, suburbanización y desurbanización. Aprovechando la excelente información que la obra de P. Cheshire y D. Hay (Cheshire y Hay, 1989) contiene en su anexo final, relativa a la distribución espacial (centro y periferia) y evolución temporal (años 1971 y 1981) de la población total de las regiones urbanas funcionales más importantes del occidente europeo (aquellas que en 1981 superaban los 330.000 habitantes), hemos calculado las tasas de crecimiento poblacional (medidas de forma exponencial, acumulativa de año en año) de cada parte de su estructura metropolitana y la fase que ocupa en el modelo de evolución metropolitana tal como fue definido en el apartado 4.2. El resultado, detallado, de los 56 RUF que superaban el millón de habitantes viene recogido en el cuadro 3.

Un análisis más global de la información disponible nos permite extraer las siguientes conclusiones:

1. Las regiones urbanas funcionales que superan el millón de habitantes habian abandonado, en su mayor parte, la fase de concentración o urbanización, y se encontraban masivamente en la última fase de la etapa de suburbanización (fase IV) y en la etapa de desurbanización (fases $\vee$ y VI). (Cuadros 4 y 5 ). 


\begin{tabular}{|c|c|c|c|c|}
\hline \multicolumn{2}{|c|}{ 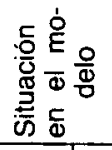 } & 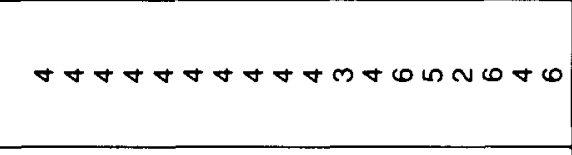 & $\forall \forall \forall \forall+$ & $0 \cos \theta \cos \theta$ \\
\hline \multirow{3}{*}{ 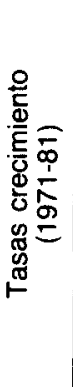 } & $\stackrel{4}{2}$ & 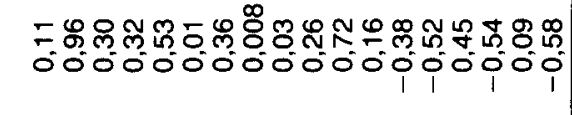 & 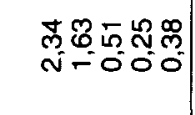 & 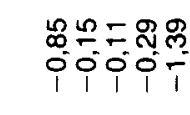 \\
\hline & $a$ & 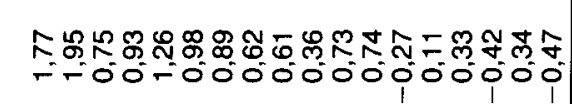 & 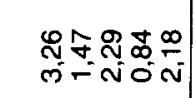 & $\begin{array}{l}0 \\
0 \infty \\
000 \\
0\end{array}$ \\
\hline & 0 & 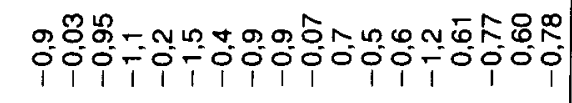 & $=\frac{m}{1} \frac{\infty}{1} \frac{m}{1}=\frac{0}{1}$ & $\begin{array}{lllll}1 & 1 & 1 & 1\end{array}$ \\
\hline \multirow{3}{*}{ 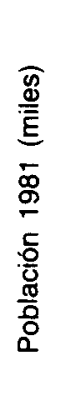 } & $\stackrel{4}{\vec{\alpha}}$ & 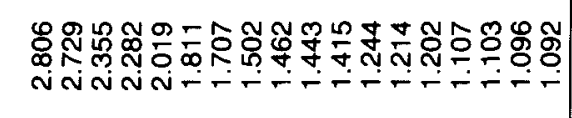 & 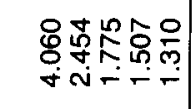 & 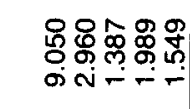 \\
\hline & $a$ & 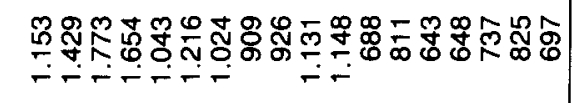 & 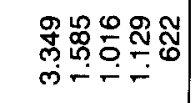 & 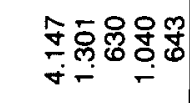 \\
\hline & 0 & 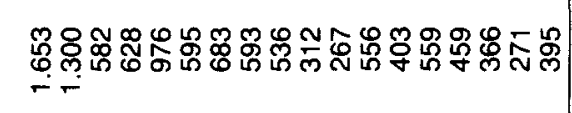 & 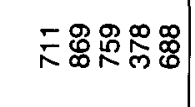 & 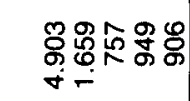 \\
\hline \multirow{3}{*}{ 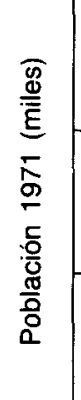 } & $\frac{u}{\grave{\alpha}}$ & 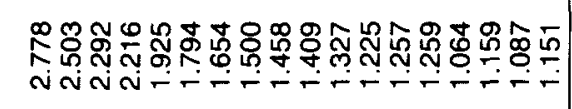 & 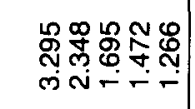 & 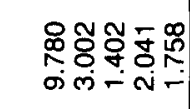 \\
\hline & 0 & 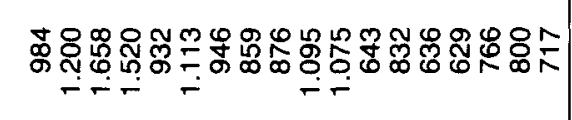 & 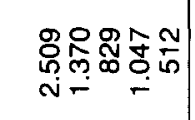 & 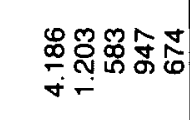 \\
\hline & 0 & 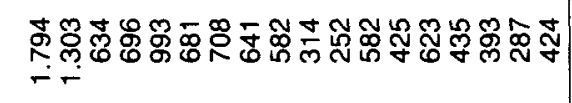 & 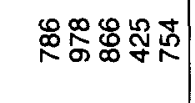 & 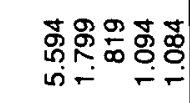 \\
\hline 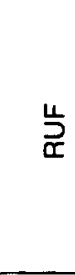 & & 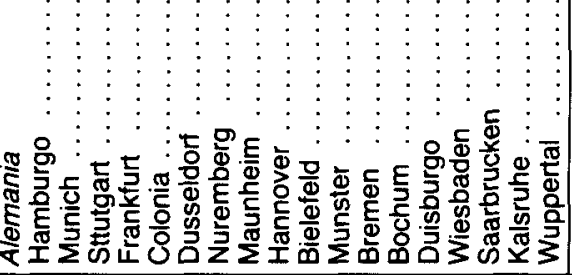 & 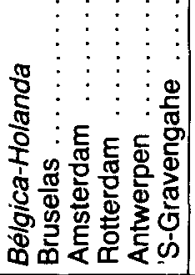 & 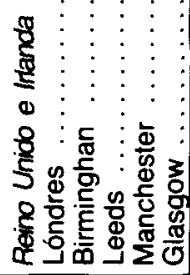 \\
\hline
\end{tabular}


La desaceleración metropolitana y su reflejo en la realidad urbana ...

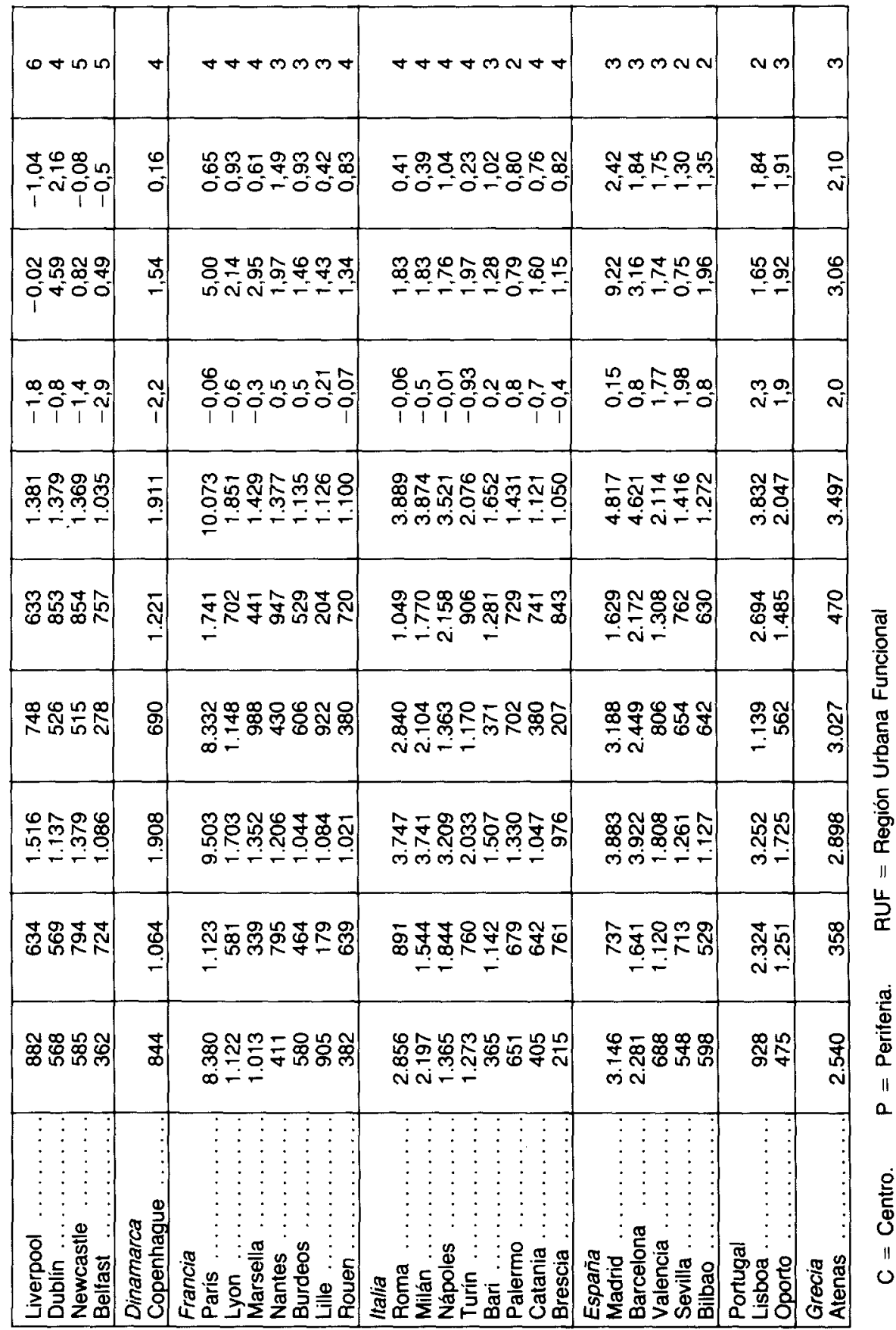


CUADRO 4. REGIONES URBANAS FUNCIONALES (millonarias) SEGÚN PAÍSES Y SITUACIÓN EN EL MODELO METROPOLITANO

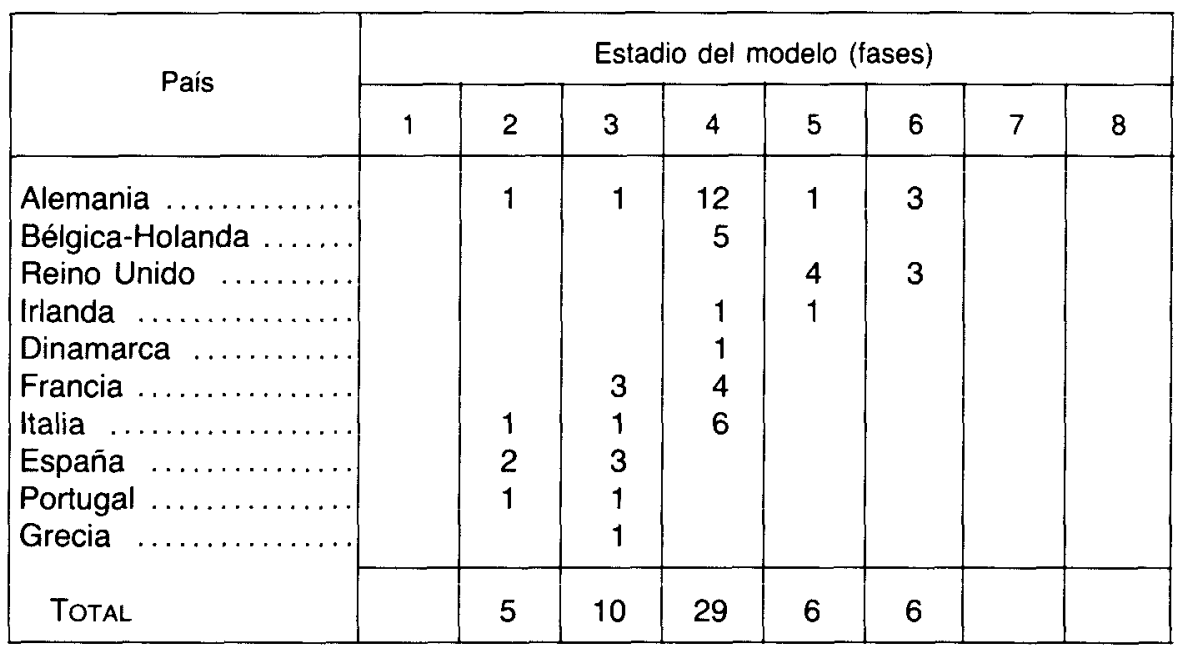

CUADRO 5. PORCENTAJE DE RUF EN CADA ETAPA DE LA EVOLUCIÓN METROPOLITANA (según tamaño)

\begin{tabular}{|c|c|c|c|c|}
\hline TAMAÑo & $\begin{array}{c}\text { CONCEN- } \\
\text { TRACION } \\
(\%)\end{array}$ & $\begin{array}{c}\text { SUBURBA- } \\
\text { NIZACIÓN } \\
(\%)\end{array}$ & $\begin{array}{c}\text { DESURBA- } \\
\text { NIZACIÓN } \\
(\%)\end{array}$ & $\begin{array}{c}\text { REURBA- } \\
\text { NIZACIÓN } \\
(\%)\end{array}$ \\
\hline $\begin{array}{c}\text { R.U.F. (millonarias) .... } \\
\text { R.U.F. (tamaño menor } \\
\text { del millón de habitan- } \\
\text { tes) .................... }\end{array}$ & 8,9 & 69,6 & 21,4 & 0 \\
\hline
\end{tabular}

2. Las áreas urbanas de menor tamaño (inferior al millón de habitantes) aún mantienen un porcentaje importante $(21$ por 100$)$ en la fase de urbanización. (Cuadros 5 y 6 ).

Observando la situación por países, el Reino Unido presentaba la posición más avanzada en el modelo. El 60,9 por 100 de sus áreas metropolitanas (Londres, Birminghan, Leeds, Manchester, Glasgow, Liverpool, Newcastle) se encontraban en la etapa de desurbanización (Cuadro 7). En el extremo opuesto se situaba España, donde un porcentaje importante de sus mayores ciudades $(81,3$ por 100$)$ se hallaba aún en proceso de atracción y concentración de la población. Únicamente las 
CUADRO 6. REGIONES URBANAS FUNCIONALES (inferiores al millón de habitantes) SEGÚN PAÍSES Y SITUACIÓN EN EL MODELO METROPOLITANO

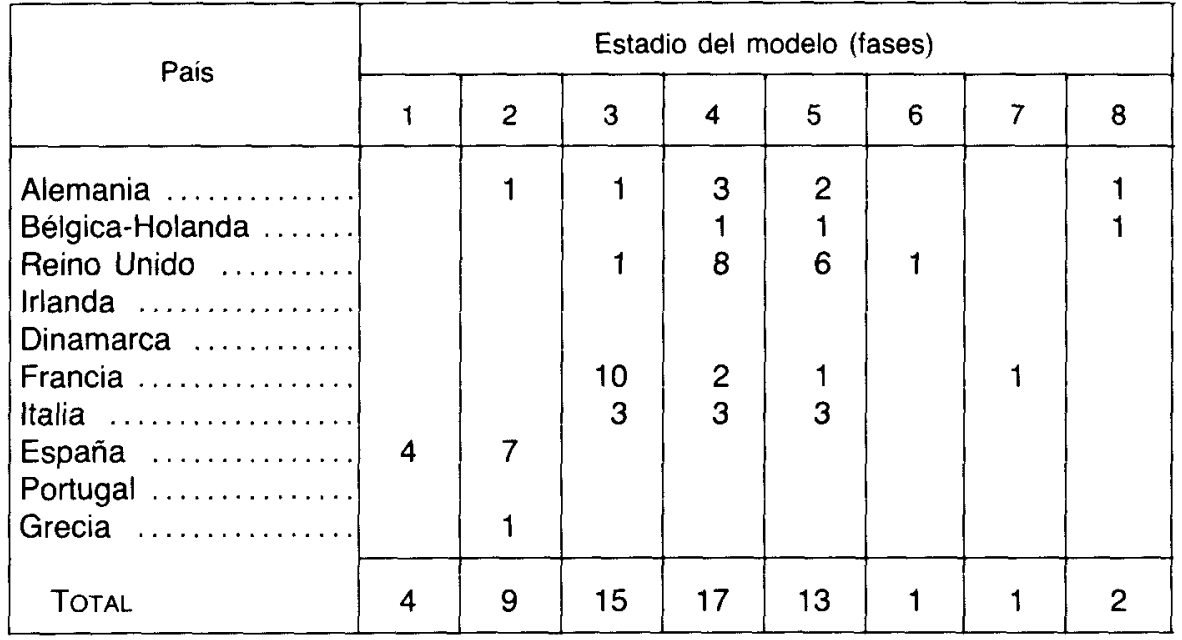

CUADRO 7. PORCENTAJE DE RUF EN CADA ETAPA DE LA EVOLUCIÓN METROPOLITANA (según países)

\begin{tabular}{|c|c|c|c|c|}
\hline PAISES & $\begin{array}{l}\text { CONCEN- } \\
\text { TRACION }\end{array}$ & $\begin{array}{l}\text { SUBURBA- } \\
\text { NIZACION }\end{array}$ & $\begin{array}{l}\text { DESURBA- } \\
\text { NIZACION }\end{array}$ & $\begin{array}{l}\text { REURBA- } \\
\text { NIZACIÓN }\end{array}$ \\
\hline Alemania & 7,7 & 65,4 & 23,1 & 3,8 \\
\hline Bélgica-Holanda & - & 75,0 & 12,5 & 12,5 \\
\hline Reino Unido .... & - & 39,1 & 60,9 & - \\
\hline Irlanda & 50,0 & 50,0 & - & - \\
\hline Dinamarca ............ & - & 100,0 & - & 一 \\
\hline Francia $\ldots \ldots \ldots \ldots \ldots$ & - & 90,5 & 4,8 & 4,8 \\
\hline Italia & 5,9 & 76,5 & 17,6 & - \\
\hline España & 81,3 & 18,3 & - & - \\
\hline Portugal & 50,0 & 50,0 & - & - \\
\hline Grecia .. & 50,0 & 50,0 & - & - \\
\hline
\end{tabular}

áreas metropolitanas de Madrid, Barcelona y Valencia habían entrado en la etapa de suburbanización.

4. En general, puede observarse una posición disimétrica entre los países del Norte europeo, más desarrollados económicamente y los me- 
diterráneos del Sur (incluida Irlanda). En general, durante el período 1971-81, el crecimiento metropolitano fue muy débil, e incluso negativo, en la mayor parte de las grandes aglomeraciones urbanas de los paises europeos de mayor nivel de desarrollo. En este sentido, destacan las siete regiones urbanas del Reino Unido, con crecimiento negativo. En el resto de los países, como Alemania, Dinamarca y Francia los crecimientos fueron débiles, no superándose en ningún caso la tasa de crecimiento del 1 por 100 anual. En Italia, puede establecerse una clara diferenciación entre las metrópolis industriales del Norte (Milán y Turín) de crecimiento más lento y las del Sur (Bary y Nápoles), de crecimiento más elevado. Las excepciones son las áreas metropolitanas de Bruselas y Amsterdam donde el crecimiento ha sido positivo y alto.

Por contra, los paises mediterráneos (incluido Irlanda) destacan por su elevado índice de crecimiento. Todas las grandes aglomeraciones urbanas superaron durante la década de los años setenta, la tasa del 1 por 100 de crecimiento anual. Destacan, en este sentido, Madrid, Atenas y Dublín que lograron sobrepasar el 2 por 100. Durante la década de los años 80 , las tendencias de desaceleración urbana también han alcanzado a estos países, lo que demuestra que la acomodación al modelo metropolitano se está verificando de manera evolutiva.

\section{CONCLUSIONES}

Las tendencias características del crecimiento desarrollista de los años cincuenta y sesenta vinieron a quebrarse con la crisis económica, modificando el ritmo de concentración de la población en grandes aglomeraciones urbanas.

La reducción del crecimiento económico ha afectado de manera desigual a los distintos sectores de la producción. El sector industrial, sobre todo en sus actividades más tradicionales, ha sufrido más el impacto de la crisis, habiendo reducido su peso respecto al sector servicios. Además, la desindustrialización ha reorganizado el tejido productivo del sector secundario sobre la base de la descentralización y segmentación de la producción.

El resultado ha sido la deslocalización y difusión de las actividades económicas en el espacio, circunstancia favorecida por la aplicación de las innovaciones tecnológicas en el campo del manejo de la información y sistemas de transporte. Los nuevos factores de localización de las empresas han privilegiado las ciudades pequeñas y medias y las áreas ru- 
rales bien equipadas, en un momento en que las economias de desaglomeración estaban dejando hacer notar su efecto negativo sobre la gran ciudad.

En este contexto, el destino de las grandes ciudades europeas se ha diversificado en función de su adaptación a las nuevas tendencias, aunque el resultado general ha sido un descenso de la población, que ha abandonado la ciudad, primero a las periferias más próximas (suburbanización) y luego a pequeñas ciudades más alejadas (desurbanización). El proceso está teniendo lugar con un cierto desfase entre las ciudades más desarrolladas del norte europeo y las mediterráneas del Sur. 


\section{BIBLIOGRAFÍA}

AYDALOT, P., 1987: “El declive urbano y sus relaciones con la población y el empleo", en Estudios Territoriales. Madrid, págs. 15-32.

BerRY, B., 1976: «Urbanization and Counterurbanization», en Urban Affairs Annual Reviews, vol. II. Beverly Hills, Sage Publications.

Blumenfeld, H., 1972: The modern metropolis. It's Origen Growth, Characteristics and Planning. Norwich, England.

CAmpos VenutTI, G., 1985: «Reestructuración económica, revolución tecnológica y nueva organización del territorio", en Metropolis, Territorio y Crisis. Madrid. Ed. Asamblea de Madrid.

CAstells, M., 1985 a: «High Tecnology, Economic Restructuring, and the Urban-Regional Process in the United States", en High Technology, Space and Society. Beverly Hills, Ed. Urban Affairs Annual Reviews, vol. 28, Sage Publications.

CAstells, M., 1985 b: “El impacto de las nuevas tecnologías sobre los cambios urbanos y regionales", en Metrópolis, Territorio y Crisis. Madrid, Ed. Asamblea de Madrid.

CheshIRE, P. y HAY, D., 1985: “Problemas de declive y crecimiento en las ciudades de Europa", en Estudios Territoriales, n. ${ }^{\circ} 19$. Madrid, págs. 31-56.

CheshiRe, P. y Hay, D., y Carbonaro, G., 1986: Urban problems in Europe: a Review and Synthesis of recent literature. Luxemburgo, CEC.

CHESHIRE, P. y HAY, D., 1989: Urban problems in Western Europe. Unwin Hyman Ltd.

ClaVAL, P., 1989: “L'avenir de la metropolisation", Annales de Geographie, n. ${ }^{\circ} 550$, págs. $692-707$.

EstebAN, A., 1981: Las Áreas metropolitanas en España: un análisis ecológico. Madrid, C.I.S.

FIELDING, A. J., 1990: “Counterurbanisation: threat or blessing?», en Western Europe: Challenge and Change. London, Belhaven Press. 
FreY, W. H., 1988: “Migración y despoblamiento de las metrópolis: ¿restructuración regional o renacimiento rural»?, en Estudios Territoriales, n. ${ }^{\circ}$ 28. Madrid, págs. 15-38.

HaLL, P. y HAY, D., 1980: Growth centres in the European urban System. London, Heinemann Educational.

HaLL, P., 1985: "Consideraciones de la crisis desde el punto de vista de las necesidades humanas", en Metropolis, Territorio y Crisis. Madrid, Ed. Asamblea de Madrid.

Isserman, A. M. y Brown, M. A., 1985: Suburbs in crisis. Totowa, Rowman and Allan held.

LAVERGNE, F., 1988: "La Europa urbana y la crisis: un primer balance después de la Conferencia de Madrid", en Revista Alfoz, n. ${ }^{\circ}$ 51, págs. 22-27.

LEVEN, C. L., 1978: The mature metropolis. Lexington.

LoNG, J. F., 1981: Population Deconcentration in the United States. Washington, Special Demographic Analysis.

MENDEZ, R., 1986: Actividad industrial y estructura territorial en la región de Madrid. Madrid. Consejería de Trabajo, Industria y Comercio, C.A.M.

RICHTER, K., 1985: “Nonmetropolitan Growth in the Late 1970s: The End of the Turnaround?", en Demography, n. ${ }^{\circ} 22$, págs. 245-262.

SANTOS, M., 1984: «La Geografia a fines del siglo Xx: nuevas funciones de una disciplina amenazada" en Revista Internacional de Ciencias Sociales. vol. XXXVI, n. 4.

SHURMER-SMITH, L. y BURTENSHAW, D., 1990: "Urban decay and rejuvenation" en Western Europe: Challenge and Change. London, Belhaven Press.

SUÁREZ VILLA, L., 1987: “Evolución metropolitana, cambio económico sectorial y distribución del tamaño de las ciudades" en Estudios Territoriales. Madrid, págs. 155-181.

SUÁREZ VILLA, L., 1988: "Reconversión industrial, cambio tecnológico y planes de desarrollo metropolitano", en Estudios Territoriales. Madrid, págs. 13-26.

TOBIN, G. A., 1979: The changing structure of the city: what happened to the urban crisis? London, Sage Publications.

VAN DEN BERG, y ALT., 1982: Urban Europe: a study of growth an decline. Oxford, Pergamon.

VINNING, D. R. y PALLONE, R., 1982: “Migration between core and peripheral regions: a description and tentative explanation of the patterns in 22 countries", en Geoforum, vol. 13, pág. 339-410.

WebBer, M. J., 1985: Industrial Location. Bervely Hills, Sage Publications. 